\title{
ARCHITECTURAL SURVEY TECHNIQUES FOR DEGRADATION DIAGNOSTICS. AN APPLICATION FOR THE CULTURAL HERITAGE
}

\author{
S. Morena ${ }^{1}$, F. Bordese ${ }^{1}$, E. Caliano ${ }^{2}$, S. Freda ${ }^{3}$, E. De Feo ${ }^{1}$, S. Barba ${ }^{1}$ \\ ${ }^{1}$ Department of Civil Engineering, University of Salerno, 84084 Fisciano (SA), Italy - (smorena, sbarba, edefeo)@unisa.it, \\ f.bordese@studenti.unisa.it \\ 2 Istemi, 84085 Mercato S. Severino (SA), Italy - e.caliano@istemi.it \\ ${ }^{3}$ Cultural Heritage and Religious Building Office, Diocese of Sessa Aurunca (CE), Italy - beniculturali@diocesisessa.it)
}

KEY WORDS: Terrestrial Laser Scanning, Photogrammetry, Non-Destructive Testing, Infrared Thermography, Data fusion, Material degradation, Historic structure.

\begin{abstract}
:
The great technological development in recent years in the field of architectural survey has made possible increasingly expeditious and less invasive investigations with the aim of acquiring a series of data related to the asset and fundamental for the protection of cultural heritage. In addition, the synergy between the various techniques represents an added value able, not only, to fill possible gaps and lacks arising from application limits of the instruments, but also to enhance the peculiarities of the same. This paper presents an integrated survey activity (range-based, image-based and IR thermography techniques) aimed at applying the combination and collaboration of multiple sensors for the analysis and study of historical buildings as well as for the generation of digital repository to support current and future investigations. In particular, the attention has been on the Chiesa dell'Annunziata located in the municipality of Sessa Aurunca in the province of Caserta (Italy). By carrying out a systematic process of survey, colorimetric-material analysis and thermographic investigations, the work has allowed to identify the main forms of degradation that characterize the structure and the causes that generate it. The work conducted through the combination of multiple technologies demonstrates, once again, the importance of synergy and integrations between several instrumentations useful for the documentation of the built heritage, characterized by complex analyses and investigations based on increasingly interdisciplinary approaches.
\end{abstract}

\section{INTRODUCTION}

The digitization of cultural heritage is a usual practice that ensures archives of digital data, which can be shared for both technical insights and simple dissemination. The great heterogeneity that characterizes architectonic buildings, however, inevitably involves the multiple combination of acquisition techniques for the generation of a unique and complete model (Moon et al., 2019; Shao et al., 2019).

Among the various monuments in our territory, churches represent an important part of architectural heritage, often structures of particular relevance from the historical and/or artistic point of view that are still frequently used today. Nevertheless, their continuous use over the centuries has inevitably led to problems of degradation, certainly caused by the passing of the years but also by human interventions and transformations that the buildings have undergone over the ages. This paper is focuses on the analysis of the potentialities offered today by some of the main survey techniques in the field of cultural heritage for the study of the built heritage, in particular for a first diagnostic investigation related to determine forms of degradation. The acquisition, in this case, was conducted entirely with non-destructive techniques such as Terrestrial Laser Scanning (TLS), Close-range photogrammetry, Unmanned Aerial Vehicle (UAV) and Infrared Thermography (IRT). That is, technologies that are quite widespread and already used in various application contexts (Biscarini et al., 2020; Plati et al., 2020) and for the study and conservation of historical architectural heritage (Carnevali et al., 2018; DizMellado et al. 2021; El-Din Fawzy, 2019; Limongiello et al., 2020; Yastikli, 2007). Greater attention, therefore, has been paid to the combination of several survey techniques with the aim of reaching an anamnesis of the degradation, mainly in proximity of the main dome (set on tambour) and the small dome of the transept facing north-east (set on spandrels). After a first laser scanner acquisition, carried out with the agile Leica BLK360, followed a close-range photogrammetric survey using a Canon EOS 760D reflex camera and an acquisition with the DJI Mavic Air 2 drone, which made possible to complete the survey of the entire building.

Further diagnostic inspections were carried out through thermographic acquisitions, performed with a FLIR T420bx, whose thermal images allowed the detection of thermographic information of the internal surface, often related to the texture of the material and/or its degradation (Kordatos et al., 2013; Moropoulou et al., 2013; Paoletti et al., 2013).

The photogrammetric survey proceeded also outside the building, where a DJI Matrice 210 drone was used to probe the roof; this operation turned out to be of fundamental importance to increase the amount of information found by direct visual inspections, allowing a greater visibility of forms of degradation even in the upper part of the edifice.

Only at a later stage, following the various surveys, it was proceeded to the generation of a single model (internal and external). The conducted surveys, in fact, had been carried out with the purpose of a localized diagnosis of the degradation and not for the generation of the complete model, reason for which we did not use ground control points during the acquisitions. Hence, the association of various methodologies and instruments has made possible to return technical drawings to ensure a first diagnostic investigation without having to operate 
with invasive and often destructive methods to ensure a respectful conservation of our historical and artistic heritage.

\subsection{Case study: Chiesa dell'Annunziata of Sessa Aurunca}

The Chiesa dell'Annunziata was erected in 1489 within the walls of the city of Sessa Aurunca in the province of Caserta. After a series of rehashes in Baroque style, following the earthquake of 1688 , the Church today presents on the facade two lateral bell towers and a luminous majolica dome surmounts it (Villucci, 1980).

The main facade is developed on two levels marked by pilasters of composite and carolithic order and has three large portals that give access to their respective naves (Diamare, 1993). The Greek cross plan preserves its Renaissance style and presents at the centre of the space four large pillars that support an entablature on which it is set, through twin arches and spandrels, the main dome (Villucci, 1995). The last one overhangs the tambour that is illuminated by four large windows and is divided by pairs of Tuscan pilasters that extend beyond the cornice to the top of the dome, where the lantern is located.

The Church in question (Figure 1) stands out in the landscape for its dome made in the 18th century and covered with blue, white and yellow majolica tiles that stand out on the roof of terracotta elements. The enamelled scales in various colours are arranged to decorate the dome with an alternation of parallel lines in alternating colours. The basic element of the majolica covering is a flat brick characterized by a rounded lower profile that better allows it to be placed side by side and favours its adaptation to curved surfaces. The anchorage of the scales to the substrate occurs by means of a hole in the upper part and the glazing involves only the outer face and the side edges that will remain visible.

Masterfully arranged, with a clever play of geometry and colour, majolica generate polychrome patterns of strong visual attraction and they are very characteristic for the surfaces of the domes.

The various restoration interventions over the years have highlighted the stratification of the building and the various changes over time. The superintendence, following some findings, has brought to light the fragments of the glazed terracotta floor, the bases of the columns in painted tuff and the frescoes on the walls, which have allowed to establish the permanence of a large part of the pre-existing Church under the present one.

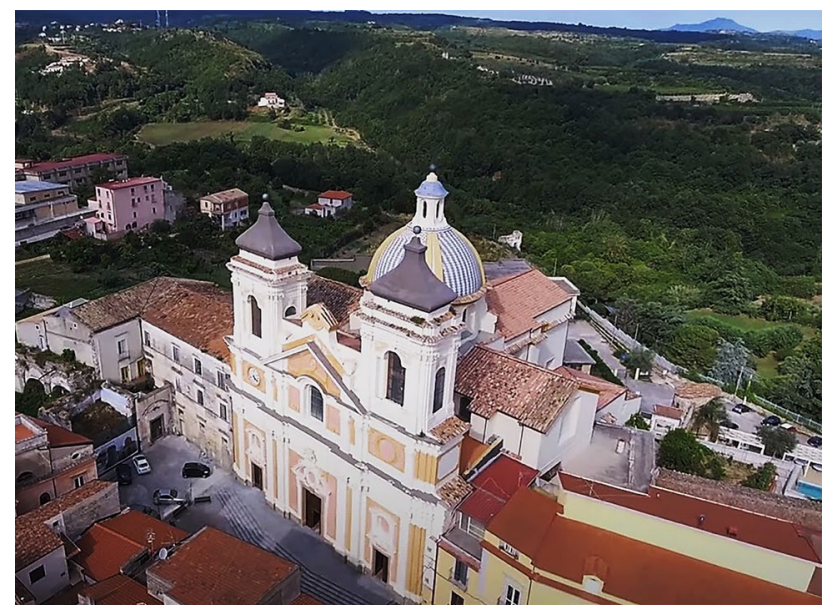

Figure 1. Chiesa dell'Annunziata, UAV photo
The Chiesa dell'Annunziata represents, therefore, a typical example of the Campanian Baroque that for its stratifications and particularities represents an example of little-known architecture on our territory to be preserve and protected.

\section{SURVEY AND DATA PROCESSING}

The current state of the Church, therefore, was surveyed through the use of various technologies and the data was postprocessed with various software. A brief description is conducted below.

\subsection{Terrestrial Laser Scanning}

In this case study a Leica BLK360 was implemented, a medium range laser scanner $(0.6 \mathrm{~m}-60 \mathrm{~m})$ characterized by a maximum acquisition speed of $360.000 \mathrm{pts} / \mathrm{s}$ and a 3D point accuracy of approximately $6 \mathrm{~mm}$ at a distance of $10 \mathrm{~m}$ (as specified by the manufacturer). The instrument uses Waze from Digitizer (WFD) technology and it is primarily designed for simple surveys characterized by medium quality (Luhmann et al., 2019).

The Leica BLK360 was used only for the interior of the Church: the acquisition phase included 22 scanning stations made in a single working day. An accuracy of $4 \mathrm{~mm}$ at $10 \mathrm{~m}$ was set during acquisition. The data acquired in this way are initially recorded in the scanner and only later, transferred via Wi-Fi to a computer or tablet to be managed with Autodesk ReCap Pro. Point cloud alignment occurs automatically when the data has the correct overlap. Otherwise, manual registration (identifying at least three homologous points) is required. The ICP (Iterative Closet Point) registration, based on the minimization of the cloud-to-cloud distance (Sharp et al., 2002; Pomerleau et al., 2015) ensured the generation of a cloud of about 145.000 .000 points. Among the various visualization modes proposed by the software, we highlights intensity, which measures the point reflectivity based on surface texture, surface angle, and the environment. This visualization mode has allowed in the case study (setting the visualization in grayscale) to localize the presence of dump stains of greater intensity with respect to the surrounding, allowing a first localization of the problem (Figure 2). The acquisitions, later on, proved to be indispensable also as a support for the alignment between the various surveys carried out in subsequent phases and through the implementation of different tools. The coordinates relative to the points cloud, in fact, have been used as a reference for the markers in the photogrammetric field, ensuring the generation of a model in real shape and size and allowing an alignment of the dense clouds with that obtained by laser scanner.

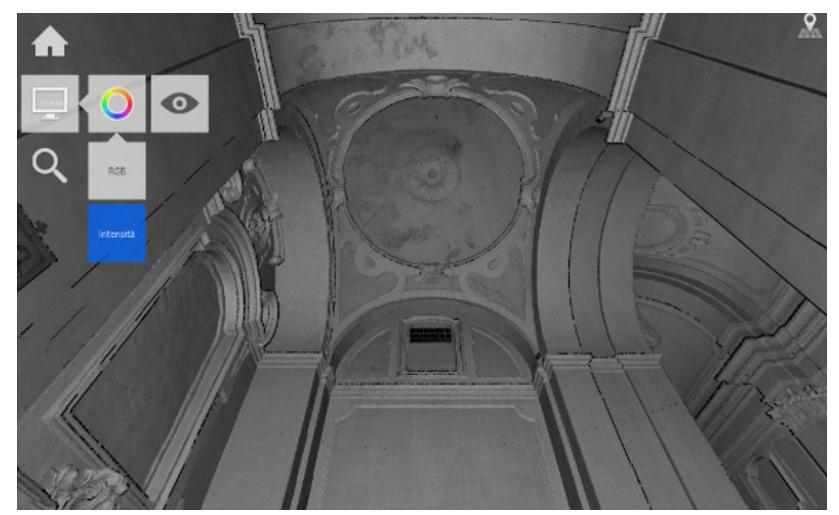

Figure 2. Intensity visualization mode in ReCap Pro 


\subsection{Close-range photogrammetry}

The survey conducted for the Chiesa dell'Annunziata included targeted close-range acquisitions within the building. In particular, attention was paid to the dome set on tambour and the lateral dome set on spandrels.

For the ground acquisitions was used the Canon EOS 760D SLR characterized by an APS-C sensor of 24 Megapixels and implemented with a focal ratio of $\mathrm{f} / 3.5$.

For each dome has been designed an acquisition in order to ensure the criteria of overlap and ensure the presence of homologous points. The total images acquired are 44 for the first dome and 40 for the small dome. For the data processing, we proceeded with the Agisoft Metashape software (version 1.7.0 build 11736) widely used in Structure for Motion (SfM) and in different application fields.

After a first phase of alignment of the photos (orientation) with consequent generation of the sparse cloud, we proceeded to the realization of the dense clouds. Below the parameters set respectively for the dome on tambour: Align photos with a value of Accuracy=Highest, Key-points $=40.000$ and Tiepoints $=4.000$ and for the generation of the Dense Cloud, Quality=High and Filtering=Mild. For the dome on spandrels: Accuracy $=$ Highest, Key-points $=40.000$ and Tie-points $=0$ and for the generation of the Dense Cloud, Quality=High and Filtering=Aggressive.

The next step involved the generation of a mesh and texturing using the same images previously processed for the export of the respective orthophotos.

\subsection{UAV photogrammetry}

For the acquisitions of the inner domes, the DJI Mavic Air 2 was used. The instrument is characterized by its small size $(183 \times 253 \times 77 \mathrm{~mm})$ and a weight of 570 gr with integrated camera: equipped with a CMOS Quad Bayer Sony IMX586 sensor $1 / 2$ " with 48 Megapixels that in photo mode, using the pixel binning, is reduced to 12 Megapixels.

The acquisitions inside the Church were made ensuring an overlap of about $70 \%$ through the implementation of fixed focal length lens $\mathrm{f} / 2.8$ and focal length of $24 \mathrm{~mm}$.

It should, however, be noted that the FOV of $70^{\circ}$ horizontally and $56^{\circ}$ vertically forward and $44^{\circ}$ horizontally and $57^{\circ}$ vertically backward, hindered the azimuthal acquisition of the dome, creating a gap in the photogrammetric model developed from the images produced by it.

For the coverage acquisitions from outside was used a DJI Matrice 210 with the ZENMUSE XS5 camera with a 20Megapixel 4/3 CMOS sensor on board. Once again, the acquired data (for both the interior and exterior) were processed with the Metashape software from the Russian manufacturer Agisoft. For the interior, the parameters setting are: Align photos with a value of Accuracy $=$ High, Key-points $=40.000$ and Tie-points $=4.000$ and for the generation of the Dense Cloud, Quality=Medium and Filtering=Mild. For the exterior: Align photos with Accuracy $=$ Highest, Key-points $=40.000$ and Tiepoints $=4,000$ and for the generation of the Dense Cloud, Quality=Ultra High and Filtering=Mild.

\subsection{Infrared Thermography}

Infrared Thermography (IRT) was used to investigate the presence of any material-constructive not homogeneities of the finishing layers, presence of humidity, thermal bridges and air infiltration of the Church.

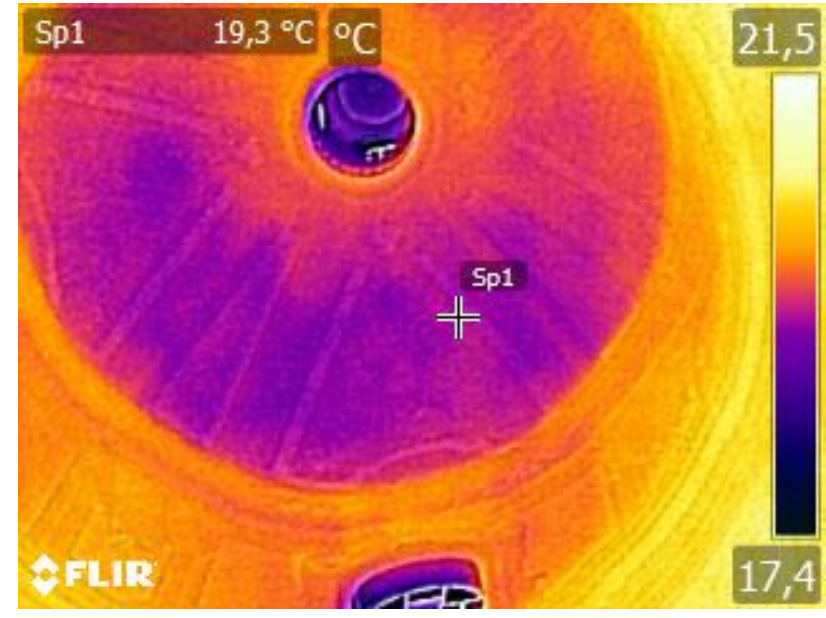

Figure 3. Thermal images visualization in FLIR Tools

Thermographic analysis, standardized by UNI EN 167141:2016, can be conducted in two modes: active or passive, and in both cases, it represents a technique that does not alter the material. In passive applications, the effects of thermal cycles are analysed through insolation and subsequent cooling that occur naturally in the environment, while in the active case, the heating of surfaces occurs artificially by the operator (Valero et al., 2019).

In the present case, we proceeded with a passive analysis of qualitative and not quantitative type, since the numerical identification of temperature values on the surfaces are not necessary since irregularities on the colour patterns and differences in intensity are sufficient to interpret data and evaluate presence of degradation in the envelopes and structures of historic buildings (De Fino and Fatiguso, 2020).

The following application involved the use of the FLIR T420bx thermal imaging camera with a rotating optical unit that allows detection from even the most difficult angles in a $25^{\circ} \times 19^{\circ}$ IR field of view. It makes pictures with a resolution of $320 \times 240$ pixels per image, for a total of 76.800 points of measurements at a minimum focusing distance of $0.4 \mathrm{~m}$.

The camera works in a temperature range from $-20^{\circ} \mathrm{C}$ to + $650^{\circ} \mathrm{C}$ in three intervals $\left(-20^{\circ} \mathrm{C}\right.$ to $+120^{\circ} \mathrm{C} ; 0^{\circ} \mathrm{C}$ to $+350^{\circ} \mathrm{C}$; $+200^{\circ} \mathrm{C}$ to $+650^{\circ} \mathrm{C}$ ) with an accuracy of $\pm 2{ }^{\circ} \mathrm{C}$. The saving format of the pictures is jpeg, to which it is possible to apply a correction of emissivity and reflected temperature, useful functions to avoid incurring in interpretation errors. The acquisitions were concentrated, once again, to the domes for the presence of an evident form of degradation and were carried out at two different times of the day: morning and afternoon. The first inspection was carried out in weather conditions of weak rain and with an environmental temperature of $11^{\circ} \mathrm{C}$. The second one was carried out with similar environmental conditions but with a temperature of $13^{\circ} \mathrm{C}$.

The software with which the images were analysed is FLIR Tools. The application allows to modify the thermal images a posteriori by selecting, among the various palettes available, the mode that guarantees a better visibility of the infiltration phenomenon (Figure 3). The main difficulties during this survey were recorded both for the disproved weather forecasts, which led to investigations during the presence of light rainfall, and for the high altitude of the intrados of the domes, not being the instrumentation mounted on drone or photographic pole. 


\section{TRHREE-DIMENSIONAL MODEL}

The investigation of the causes of humidity present inside the Church has been the cardinal reason of the survey. However, the various acquisitions conducted during the different surveys and in localized areas of the Church, allowed the realization of a unique model (interior and exterior) obtained by the assembly of various acquisitions even if lacking a georeferentiation.

In the literature there are various experiences of manual (Murtiyoso and Grussenmeyer, 2018; Lachat et al., 2016) and automatic registration (Weber et al., 2015; Yang and Zang, 2014), in the following case study, however, being decomposed surveys made in several phases and lacking ground control points, it was necessary to proceed in manual mode through the identification of homologous points and the assignment of the same spatial coordinates. Subsequently, all models have been exported in E57 format and imported in the third open source software CloudCompare (version 2.12 alpha).

In order to ensure proper union, it was possible to improve the registration through the ICP algorithm (Iterative Closest Point). The model (internal and external) thus generated has been used for the realization of graphic designs (Figure 4).
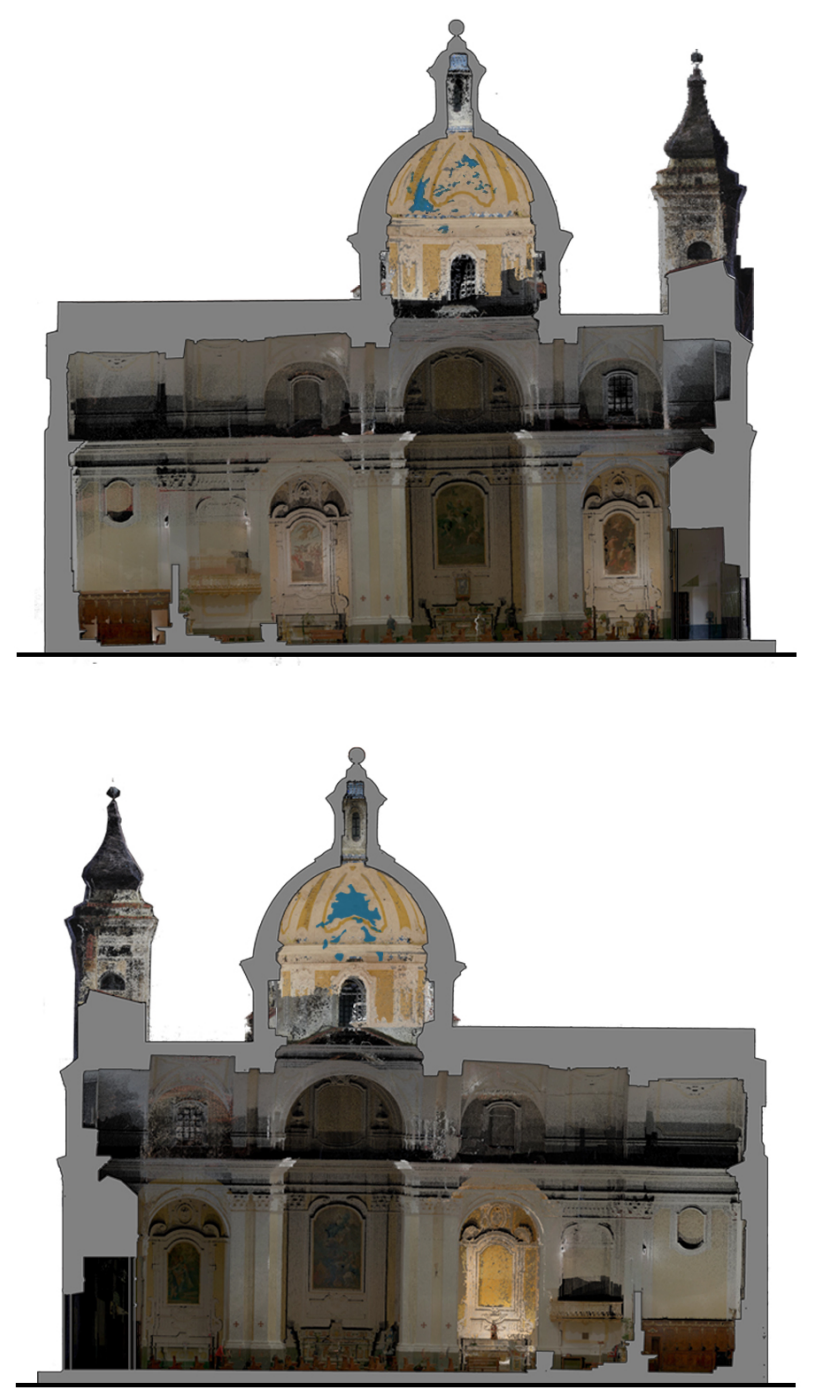

\section{DIAGNOSTICS}

In the field of cultural heritage, as is known, Non-Destructive Testing (NDT), allow to acquire extensive and reliable information in a preliminary cognitive phase that is as little invasive as possible and play a key role in the process of knowledge, analysis and control of historic buildings. As in the case study in which the appearance of physiological and pathological obsolescence phenomena occurs, NDT acts as a decision support for diagnosis of the state of conservation of the building.

The point cloud obtained from the laser scanning survey prove to be supportive for a quick inspection of the entire building as well as a metric reference base. Subsequent internal photogrammetric investigations allowed for the detection of visible stains, understood as localized chromatic variation of the surface, related to the presence of foreign materials such as water and possible organic substances and microorganisms, visible in the form of patinas. In limited areas, moreover, some detachments of the plaster can be seen that allow a glimpse of chromatic gaps.
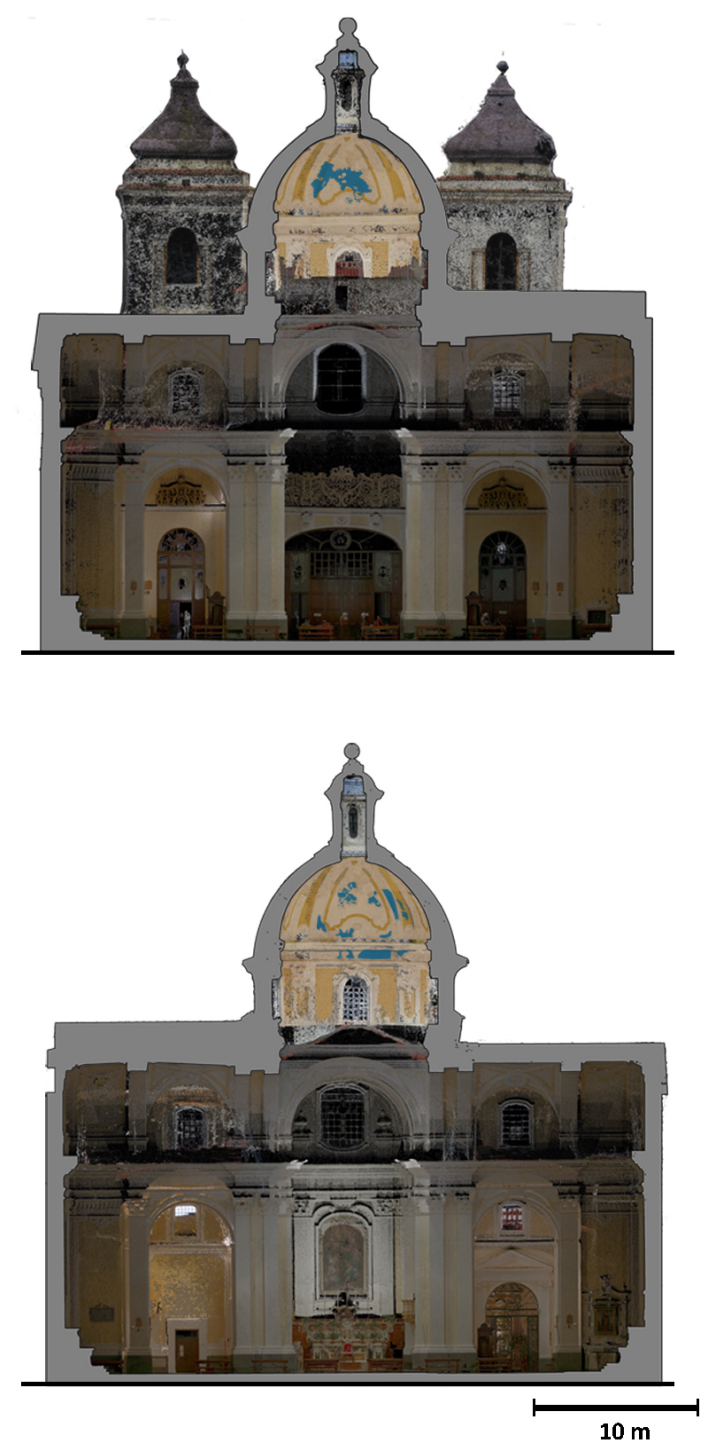

Figure 4. Sections of the Church with some moisture stains of the dome highlighted in blue: South longitudinal section, West cross section, North longitudinal section and East cross section 


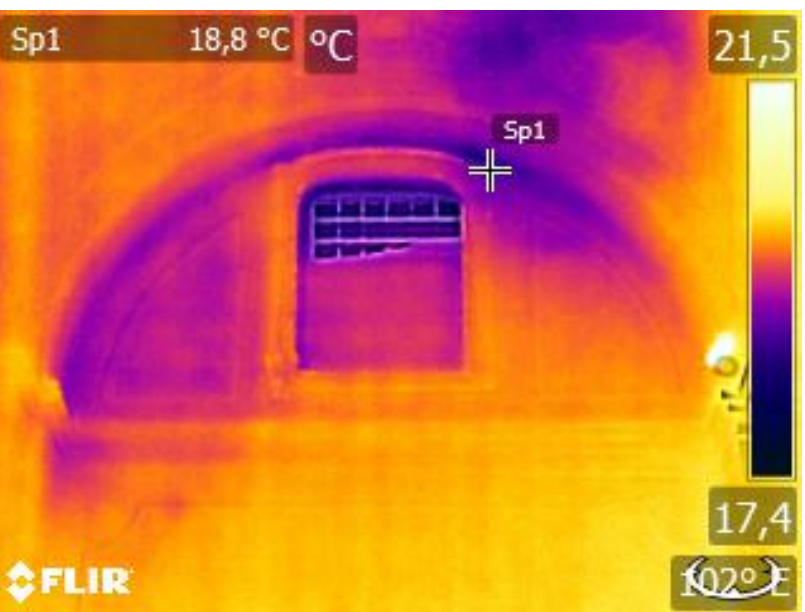

Figure 5. Moisture along the arch of the perimeter wall

The thermal image, finally, shows an evident irregular temperature map with a humidity level of greater extension than that visible on the surface by photogrammetric survey. Moisture in the walls reduces the resistance to heat transmission, depending on the amount of water retained, resulting in lower temperatures.

Moisture at the intrados of the roofs, in fact, is characterized, within the images, by a blue/violet coloration and in the case study is localized mainly in the central part of the domes and, for the dome on spandrels, along the arch of the perimeter wall (Figure 5). The flight with the drone DJI Matrice 210 has allowed visual investigations of the roof, which have proved to be decisive for the identification of degradation. Humidity at the intrados of the roof, in fact, seems to come from infiltration of meteoric origin, caused by an inadequate retention system and/or an inefficient system of rainwater disposal, favouring the penetration in different degrees in the masonry. Among the most evident forms of instability, a widespread discontinuity of the majolica tiles on the central dome of the Church stands out. From the pictures taken, in fact, it is possible to notice, in some portions of the dome, the absence of connection between the various elements that leave uncovered the various anchoring holes. In some points of the majolica covering, moreover, the instability is highlighted even more by the interruption of the wise chromatic alternation that distinguishes these types of dome, object of artistic and cultural value.

\section{CONCLUSIONS AND FUTURE DEVELOPMENTS}

The investigation work carried out in an integrated way using the different technologies of laser scanning, photogrammetry and thermography, has shown the importance of the knowledge factor in the approach to historical buildings.

Laser scanning and photogrammetric surveys allow to obtain precise metric information, as well as to guarantee the generation of graphic works of fundamental importance for the identification and localization of degradation. In addition to these surveys, thermographic surveys are able to return a superficial thermal map of the structure in order to detect anomalies related to the degradation of the material and the less superficial layers of the face. The synergy between several techniques, in fact, allows to fill information gaps that each instrument could report during the application phases of the survey and, at the same time, integrates with additional information the acquisitions of the individual one.

In the case study, the combination of different technologies has allowed, through the identification of homologous points, the restitution of a complete $3 \mathrm{D}$ model in which each point of the cloud holds more information simultaneously: spatial coordinates $(\mathrm{x}, \mathrm{y}, \mathrm{z})$ reproducible from the laser scanning survey; colorimetric (R, G, B) and material from photogrammetric survey and thermographic data, interrogating the IFOV of the frames (Figure 6). The use of these technologies could be included in a whole of testing, flanked, possibly, by other non-invasive survey tools, to reach the creation of a store of digital data, to be made available to professionals and to be implemented for possible subsequent interventions. With planned surveys and inspections, in fact, it would be possible to observe the variations of any instability and/or return a mapping of degradation over time.

On the whole, this paper shows, once again, how the combination of several surveying and diagnostic instruments is essential for the analysis and safeguarding of the architectural heritage, providing valuable information to assist any restoration or recovery interventions.

\section{ACKNOWLEDGEMENTS}

We acknowledge the collaboration of the engineers Nicolino Messuti and Carmine Napoli and we are grateful to the sacristy of the Chiesa dell'Annunziata for the availability shown during the various surveys and for the valuable historical information provided to us.

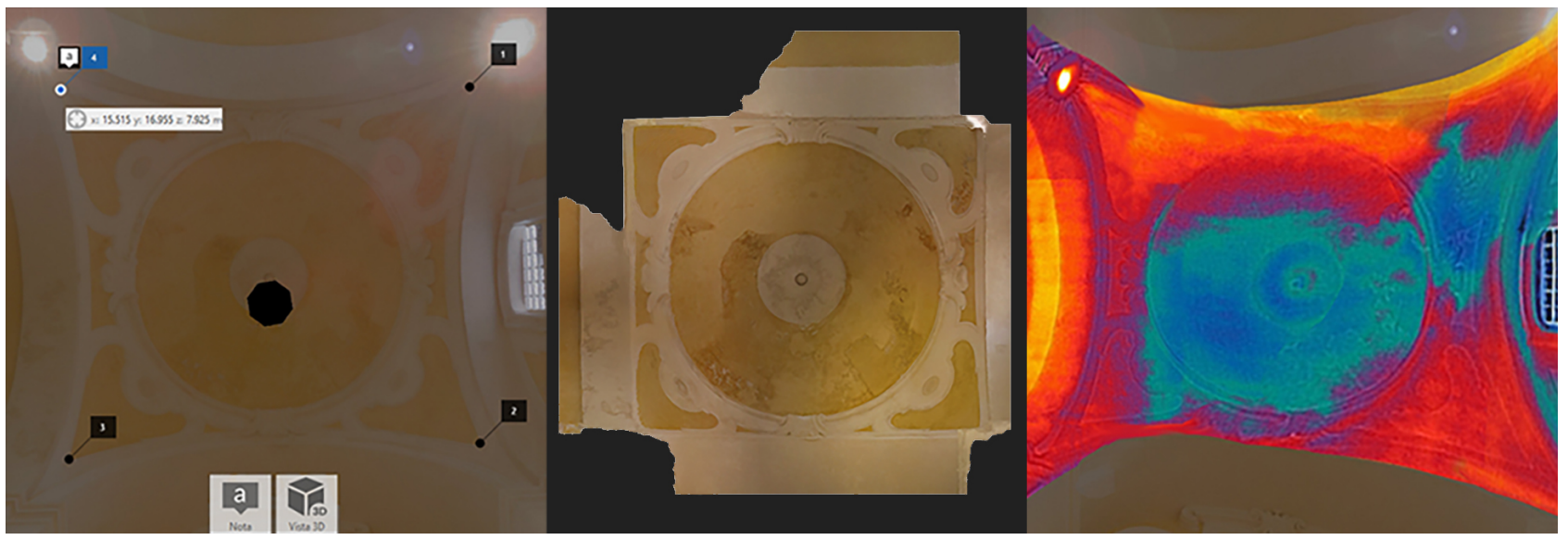

Figure 6. Dome acquisition using range-based, image-based, and IR thermography techniques 


\section{REFERENCES}

Biscarini, C., Catapano, I., Cavalagli, N., Ludeno, G., Pepe, F.A., Ubertini, F., 2020: UAV photogrammetry, infrared thermography and GPR for enhancing structural and material degradation evaluation of the Roman masonry bridge of Ponte Lucano in Italy. NDT \& E International, Vol. 115, 102287, ISSN 0963-8695. https://doi.org/10.1016/j.ndteint.2020.102287.

Carnevali, L., Ippoliti, E., Lanfranchi, F., Menconero, S., Russo, M., and Russo, V., 2018: Close-range mini-UAVs photogrammetry for architecture survey. Int. Arch. Photogramm. Remote Sens. Spatial Inf. Sci., XLII-2, 217-224. https://doi.org/10.5194/isprs-archives-XLII-2-217-2018.

De Fino, M., Fatiguso, F., 2020: La diagnostica per gli edifici storici. Edicom Edizioni.

Diamare, G.M., 1993: Memorie critico-storiche della chiesa di Sessa Aurunca. Pubbliscoop Edizioni.

Diz-Mellado, E., Mascort-Albea, E. J., Romero-Hernández, R., Galán-Marín, C., Rivera-Gómez, C., Ruiz-Jaramillo, J., Jaramillo-Morilla, A, 2021: Non-destructive testing and Finite Element Method integrated procedure for heritage diagnosis: The Seville Cathedral case study. Journal of Building Engineering, 1-17. https://doi.org/10.1016/J.JOBE.2020.102134.

El-Din Fawzy, H., 2019: 3D laser scanning and close-range photogrammetry for buildings documentation: A hybrid technique towards a better accuracy. Alexandria Engineering Journal, 58(4), 1191-1204. https://doi.org/10.1016/j.aej.2019.10.003.

Kordatos, E.Z., Exarchos, D.A., Stavrakos, C., Moropoulou, A., Matikas, T.E., 2013: Infrared thermographic inspection of murals and characterization of degradation in historic monuments. Construction and Building Materials, Vol. 48, 1261-1265, ISSN0950-0618. https://doi.org/10.1016/j.conbuildmat.2012.06.062.

Lachat, E., Landes, T., Grussenmeyer, P., 2016: Combination of TLS Point Clouds and 3D Data From Kinect V2 Sensor to Complete Indoor Models. Int. Arch. Photogramm. Remote Sens. Spatial Inf. Sci., Vol. XLI-B5, 659-666. 10.5194/isprsarchivesXLI-B5-659-2016.

Limongiello, M., Gujski, L. M., De Vita C. B., 2020: Analysis of RGB Images to Enhance Archaeological Cropmark Detection: the Case Study of Nuceriola, Italy. In 42th International Conference of Representation Disciplines Teachers Congress of Unione Italiana per il Disegno. 10.3280/oa-548.128.

Luhmann, T., Chizhova, M., Gorkovchuk, D., Hastedt, H., Chachava, N., and Lekveishvili, N., 2019: Combination of Terrestrial Laser Scanning, UAV and close-range photogrammetry for 3D reconstruction of complex churches in Georgia. Int. Arch. Photogramm. Remote Sens. Spatial Inf. Sci., XLII-2/W11, 753-761. https://doi.org/10.5194/isprs-archivesXLII-2-W11-753-2019.

Moon, D., Chung, S., Kwon, S., Seo, J., Shin, J., 2019: Comparison and utilization of point cloud generated from photogrammetry and laser scanning: 3D world model for smart heavy equipment planning. Automation in Construction, 98, 322-331. https://doi.org/10.1016/j.autcon.2018.07.020.
Moropoulou, A., Labropoulos, K. C., Delegou, E. T., Karoglou, M., Bakolas A., 2013: Non-destructive techniques as a tool for the protection of built cultural heritage. Construction and Building Materials, Vol. 48, 1222-1239, ISSN 0950-0618. https://doi.org/10.1016/j.conbuildmat.2013.03.044.

Murtiyoso, A., Grussenmeyer, P., 2018: Comparison and assessment of 3D registration and georeferencing approaches of point clouds in the case of exterior and interior heritage building recording. Int. Arch. Photogramm. Remote Sens. Spatial Inf. Sci., XLII-2, 745-751. https://doi.org/10.5194/isprsarchives-XLII-2-745-2018.

Paoletti, D., Ambrosini, D., Sfarra, S., Bisegna, F., 2013: Preventive thermographic diagnosis of historical buildings for consolidation. Journal of Cultural Heritage, Vol. 14, Issue 2, 116-121, ISSN 12962074. https://doi.org/10.1016/j.culher.2012.05.005.

Plati, C., Loizos, A., Gkyrtis, K., 2020: Integration of nondestructive testing methods to assess asphalt pavement thickness, NDT \& E International, Vol. 115, 102292, ISSN 0963-8695. https://doi.org/10.1016/j.ndteint.2020.102292.

Pomerleau, F., Colas, F., Siegwart, R. A, 2015: A Review of Point Cloud Registration Algorithms for Mobile Robotics. Found. Trends Robot, 4, 1-104. 10.1561/2300000035

Shao, J., Zhang, W., Mellado, N., Grussenmeyer, P., Li, R., Chen, Y., Wan, P., Zhang, X., Cai, S., 2019: Automated markerless registration of point clouds from TLS and structured light scanner for heritage documentation. Journal of Cultural Heritage, 35, 16-24. https://doi.org/10.1016/j.culher.2018.07.013.

Sharp, G. C., Lee, S. W., Wehe, D. K., 2002: ICP registration using invariant features. IEEE Transactions on Pattern Analysis and Machine Intelligence, vol. 24, no. 1, 90-102, doi: $10.1109 / 34.982886$.

Valero, L. R., Flores Sasso V., Prieto Vicioso E., 2019: In situ assessment of superficial moisture condition in façades of historic building using non-destructive techniques. Case Studies in Construction Materials, Vol. 10, e00228, ISSN 2214-5095, https://doi.org/10.1016/j.cscm.2019.e00228.

Villucci, A. M., 1980: I monumenti di Sessa Aurunca. Armando. Caramanica Editore.

Villucci, A. M., 1995: Sessa Aurunca storia ed arte. Caramanica Editore.

Weber, T. R., Hänsch, O., Hellwich, 2015: Automatic registration of unordered point clouds acquired by Kinect sensors using an overlap heuristic. Int. Arch. Photogramm. Remote Sens. Spatial Inf. Sci., Vol. 102, 2015, Pages 96-109, ISSN0924-2716, https://doi.org/10.1016/j.isprsjprs.2014.12.014.

Yang, B., Zang, Y., 2014: Automated registration of dense terrestrial laser-scanning point clouds using curves. Int. Arch. Photogramm. Remote Sens. Spatial Inf. Sci., Vol. 95, 109-121, ISSN 0924-2716, https://doi.org/10.1016/j.isprsjprs.2014.05.012.

Yastikli, N., 2007: Documentation of cultural heritage using digital photogrammetry and laser scanning. Journal of Cultural Heritage, Vol. 8, Issue 4, 423-427, ISSN 1296-2074, https://doi.org/10.1016/j.culher.2007.06.003. 